\title{
The Primary Complete Mitochondrial Genome of the Lappet Moth Brahmophthalma hearseyi (Lepidoptera: Brahmaeidae) and Related Phylogenetic Analysis
}

\author{
Shan Yang, Shangren Gao, Shiyu Cai, Zhiwen Zou, Tianrong Xin and Bin Xia * $\mathbb{D}$
}

Citation: Yang, S.; Gao, S.; Cai, S.; Zou, Z.; Xin, T.; Xia, B. The Primary Complete Mitochondrial Genome of the Lappet Moth Brahmophthalma hearseyi (Lepidoptera: Brahmaeidae) and Related Phylogenetic Analysis. Insects 2021, 12, 973. https:// doi.org/10.3390/insects12110973

Academic Editor: Mauro Mandrioli

Received: 8 September 2021

Accepted: 25 October 2021

Published: 28 October 2021

Publisher's Note: MDPI stays neutral with regard to jurisdictional claims in published maps and institutional affiliations.

Copyright: (c) 2021 by the authors. Licensee MDPI, Basel, Switzerland. This article is an open access article distributed under the terms and conditions of the Creative Commons Attribution (CC BY) license (https:// creativecommons.org/licenses/by/ $4.0 /)$.
School of Life Sciences, Nanchang University, Nanchang 330031, China; yangshan0794@126.com (S.Y.); banshouren0011@163.com (S.G.); caishiyu_xiaoyuer@126.com (S.C.); zouzhiwen@ncu.edu.cn (Z.Z.); xintianrong@ncu.edu.cn (T.X.)

* Correspondence: xiabin9@163.com

Simple Summary: In this paper, the complete mitochondrial genome (mitogenome) of B. hearseyi was sequenced using long-PCR and primer-walking methods. The results indicated that the mitogenome is a typical circular molecule that is composed of 15,442 bp. Phylogenetic analysis showed that B. hearseyi is clustered into Brahmaeidae, and the phylogenetic relationships are (Brahmaeidae + Lasiocampidae $)+($ Bombycidae $+($ Sphingidae + Saturniidae $))$. This study provides the first mitogenomic resources for the Brahmaeidae.

Abstract: Background: Brahmophthalma hearseyi (Lepidoptera: Brahmaeidae) is widely distributed across China. Its larvae damage the leaves of many plants such as those belonging to the Oleaceae family, causing significant economic losses and seriously affecting the survival and reproduction of Cervus nippon; however, genetic data for this species are scarce. Methods: The complete mitochondrial genome (mitogenome) of B. hearseyi was sequenced using long-PCR and primer-walking methods. Phylogenetic analysis that was based on 13 PCGs and two rRNAs was carried out using the neighborjoining and Bayesian interference methods. Results: The mitogenome is a typical circular molecule that is made up of 15,442 bp, which includes 13 protein-coding genes (PCGs), 2 ribosomal RNA (rRNA) genes, 22 transfer RNA (tRNA) genes, and an A + T-rich region (456 bp). All of the PCGs, except for COX1 and COX2, start with ATN codons. COX2 and ND5 use the incomplete termination codon T, and 11 other PCGs use the typical stop codon TAA. All tRNA genes, except for trnS1 and trnS2, display a typical cloverleaf structure; trnS1 lacks the "DHU” arm, whereas trnS2 exhibits two mismatched base pairs in the anticodon stem. Phylogenetic analysis showed that $B$. hearseyi is clustered into Brahmaeidae, and the phylogenetic relationships are (Brahmaeidae + Lasiocampidae) $+($ Bombycidae $+($ Sphingidae + Saturniidae $))$. Conclusions: This study provides the first mitogenomic resources for the Brahmaeidae.

Keywords: Brahmophthalma hearseyi; mitochondrial genome; Bombycoidea; Lasiocampoidea phylogenetic analysis

\section{Introduction}

Brahmophthalma hearseyi (Lepidoptera: Brahmaeidae) is distributed in China, Sikkim, India, Burma, Indonesia, and other countries. Its larvae damage various plants, specifically Oleaceae plants. Most of these plants have important economic value; they are important medicinal plants such as Forsythia suspensa and Ligustrum lucidum, perfume plants such as Osmanthus fragrans and Jasminum sambac, and oil plants such as Olea europaea. A larva can eat up 16 to 25 leaves per day [1-3]. As such, an outbreak of $B$. hearseyi can cause serious damage to these plants and contribute to large economic losses. Our survey found a large number of B. hearseyi in Jiangxi Taohongling National Nature Reserve [4], which cause serious damage to Oleaceae plants and seriously impact the survival and 
reproduction of Cervus nippon (which is already a critically endangered animal in China) [5]. Despite its potential economic impact, little is known about B. hearseyi [3]. Furthermore, it is morphologically and ecologically very similar to Brahmaea wallichii, but the adult size is slightly smaller [3]. Molecular information should provide more evidence for its identification.

The animal mitogenome is a double-stranded circular DNA molecule and is commonly 15-20 kb in size. It encodes 37 conserved genes, including 13 protein-coding genes (PCGs), 2 ribosomal RNA (rRNA) genes, 22 transfer RNA (tRNA) genes, and noncoding control regions that regulate its transcription and replication [6,7]. Furthermore, the mitogenome represents maternal inheritance, with a highly conserved phylogeny, non-recombination, a small size, stable structure, and easy purification [8,9]. Thus, mitogenomes are studied in several fields, such as systematic classification, molecular phylogeny, molecular evolution, population genetics, systematic geography, and molecular markers [8,10]. With the development of molecular methods in recent years, an increasing number of mitogenomes have been sequenced. To date, more than 200 Lepidoptera mitogenome sequences are available [11-14].

Lepidoptera is one of the largest insect orders worldwide with more than 165,000 species. There are 10 species classification methods, although some of the classification ideas or classification concepts that are based on traditional morphological characteristics suffer from much controversy, especially regarding the taxonomic status of Bombycoidea, Lasiocampoidea, and Sphingoidea $[15,16]$. Most scholars classify Lasiocampidae as Bombycoidea, while some scholars regard it as independent Lasiocampoidea. The classification features of Bombycoidea are mainly composed of missing or degraded morphology of the adults, and there are different classification systems that are proposed by Scoble [17], Heppner [18], and Wang [19]. The systematic classification system mainly takes the characteristics of the male external genitalia and the morphological differences of adult wing patterns as an important basis for classification [20-22]. Other classification methods are based on morphological or molecular characteristics [23]. At present, there is no molecular sequencing of the mitogenomes of $B$. hearseyi and other species of Brahmaeidae. It is important to study the mitogenome of $B$. listensey $i$ to clarify the classification method of the Bombycoidea superfamily. In this study, the mitogenome of $B$. hearsey $i$ was analyzed, and the taxonomic status of Bombycoidae, Lasiocampoidea, and Sphingoidea was discussed based on their mitogenomes. The results of this study can provide an important theoretical basis for their identification.

\section{Materials and Methods}

\subsection{Sample Collection}

Adult B. hearseyi were collected from the Pengze Taohongling Sika Deer National Nature Reserve in Jiangxi, China. Fresh samples were preserved in $100 \%$ ethanol and stored in a $-20{ }^{\circ} \mathrm{C}$ refrigerator for subsequent DNA extraction.

\subsection{DNA Extraction}

DNA from the muscle and connective tissue of adult individuals was obtained using the Qiagen DNeasy Tissue Kit [24].

\subsection{PCR Amplification and Sequencing}

Partial fragments of the COX1, COX3, ND4, CYTB, and $12 S$ genes were amplified using a lepidopteran universal primer $[25,26]$. The sequences were aligned with nucleotide databases in NCBI to confirm their identity. The primers of five long fragments (COX1COX2, COX3-ND4, ND4-CYTB, CYTB-12S, and 12S-COX1) were designed according to the sequences of five short fragments that were sequenced using Primer Premier 5.0 software [27]. The 10 primer pairs are listed in Supplementary Table S1.

Next, $2 \times$ Mix Taq DNA polymerase was used to amplify the fragments that were less than $1 \mathrm{~kb}$, whereas LA Taq DNA polymerase was used for fragments that were more 
than $1 \mathrm{~kb}$ in size. PCR cycling conditions were as follows: initial denaturation for $4 \mathrm{~min}$ at $94{ }^{\circ} \mathrm{C}$, 35 cycles of denaturation for $10 \mathrm{~s}$ at $98^{\circ} \mathrm{C}$, annealing for $30 \mathrm{~s}$ at $50-55^{\circ} \mathrm{C}$, elongation for $1-4 \mathrm{~min}$ at $72{ }^{\circ} \mathrm{C}$, and a final elongation step at $72{ }^{\circ} \mathrm{C}$ for $5 \mathrm{~min}$. The PCR products were examined through electrophoresis on a $1.0 \%$ agarose gel and stained with ethidium bromide.

\subsection{Sequence Assembly, Annotation, and Analysis}

Long- and short-fragment sequences were assembled using SeqMan software [28]. Based on the original sequencing peak figure, the results were manually corrected, the space partition was removed, and the errors in the bases were corrected to ensure sequence accuracy.

The PCGs, rRNA genes, and tRNA genes were identified using the MITOS Web Server (mitos.bioinf.uni-leipzig.de/index.py, accessed on 8 August 2021) [29]. ORF software through the NCBI website (https: / / www.ncbi.nlm.nih.gov/orffinder/, accessed on 8 August 2021) was also used to verify the annotated protein-coding genes.

The sequence length, base content, codon usage, and amino-acid composition were statistically analyzed using Editseq and MEGA 5.0 [30]. The bias of nucleotide composition was measured as AT skewness (AT skewness $=(\mathrm{A}-\mathrm{T}) /(\mathrm{A}+\mathrm{T}))$ and $\mathrm{GC}$ skewness $(\mathrm{GC}$ skewness $=(G-C) /(G+C))$.

The mitogenome sequence data of $B$. hearseyi were deposited in the GenBank database under the accession number KU884326.

\subsection{Phylogenetic Analysis}

A total of 13 PCGs and 2 rRNA genes of 20 lepidopteran mitogenomes and the mitogenome of Drosophila melanogaster were downloaded from GenBank. D. melanogaster was used as an outgroup. Two combined datasets (PCG and rRNA datasets) are concatenated with 13 PCGs and 2 rRNA genes of 22 mitogenomes in Table 1. These PCGs and rRNA genes were aligned using MEGA 5.0 and Clustal $\times 1.83$ [31]. The phylogenetic analysis was based on 13 PCGs and 13 PCGs + 2 rRNAs using neighbor-joining (NJ) [32] and Bayesian inference (BI) [33] methods (Table 1).

Table 1. The available insect mitogenomes (1 new and 24 obtained from GenBank) and their characteristics.

\begin{tabular}{|c|c|c|c|c|c|c|c|}
\hline \multirow[b]{2}{*}{ Family } & \multirow[b]{2}{*}{ Species } & \multicolumn{2}{|c|}{ Whole Genome } & \multirow{2}{*}{$\begin{array}{c}\mathrm{PCG} \\
\mathrm{A}+\mathrm{T} \\
(\%)\end{array}$} & \multirow{2}{*}{$\begin{array}{c}\text { rRNA } \\
\begin{array}{c}\text { A + T } \\
(\%)\end{array}\end{array}$} & \multirow[b]{2}{*}{$\begin{array}{c}\text { GenBank } \\
\text { Accession No. }\end{array}$} & \multirow[b]{2}{*}{ References } \\
\hline & & $\begin{array}{l}\text { Size } \\
(\mathrm{bp})\end{array}$ & $\begin{array}{c}\mathbf{A}+\mathrm{T} \\
(\%)\end{array}$ & & & & \\
\hline Saturniidae & Actias selene & 15,236 & 78.91 & 77.36 & 83.73 & NC_018133 & Liu 2012 \\
\hline Saturniidae & Antheraea pernyi & 15,566 & 80.16 & 78.47 & 83.87 & NC_004622 & Liu 2008 \\
\hline Saturniidae & Antheraea yamamai & 15,338 & 80.29 & 78.94 & 84.14 & EU726630 & Kim 2009 \\
\hline Geometridae & Biston panterinaria & 15,517 & 79.55 & 77.39 & 85.27 & NC_020004 & Yang 2012 \\
\hline Geometridae & Biston suppressaria & 15,628 & 79.43 & 77.28 & 84.92 & NC_027111 & Chen 2015 \\
\hline Bombycidae & Bombyx mandarina & 15,928 & 81.68 & 79.69 & 85.19 & NC_003395 & Yukuhiro 2002 \\
\hline Bombycidae & Bombyx mori & 15,666 & 81.35 & 79.57 & 84.82 & KM̄̄875545 & Zhang 2014 \\
\hline Brahmaeidae & Brahmophthalma hearseyi & 15,442 & 80.81 & 79.27 & 83.87 & KU884326 & This study \\
\hline Lasiocampidae & Dendrolimus punctatus & 15,411 & 79.46 & 77.62 & 84.73 & NC_027156 & Qin 2015 \\
\hline Lasiocampidae & Dendrolimus spectabilis & 15,411 & 79.5 & 77.71 & 83.68 & NC_025763 & Tang 2011 \\
\hline Pyralidae & Ephestia kuehniella & 15,295 & 79.76 & 78.18 & 84.44 & NC_022476 & Traut 2013 \\
\hline Saturniidae & Eriogyna pyretorum & 15,327 & 80.82 & 79.41 & 84.55 & NC_012727 & Jiang 2009 \\
\hline Lymantriidae & Euproctis pseudoconspersa & 15,461 & 79.93 & 77.99 & 84.87 & NC_027145 & Dong 2016 \\
\hline Pyralidae & Galleria mellonella & 15,320 & 80.42 & 78.88 & 84.37 & NC_028532 & unpublished \\
\hline Crambidae & Haritalodes derogata & 15,235 & 80.7 & 79.19 & 84.59 & NC_029202 & Zhao 2015 \\
\hline Geometridae & Jankowskia athleta & 15,534 & 79.53 & 77.71 & 83.83 & NC_027948 & Xu 2015 \\
\hline Lymantriidae & Lymantria dispar & 15,569 & 79.88 & 77.84 & 84.6 & NC_012893 & Zhu 2010 \\
\hline Sphingidae & Manduca sexta & 15,516 & 81.79 & 80.3 & 85.42 & NC_010266 & Cameron 2008 \\
\hline Geometridae & Phthonandria atrilineata & 15,499 & 81.02 & 79.1 & 85.93 & NC_010522 & Yang 2009 \\
\hline Bombycidae & Rondotia menciana & 15,301 & 78.86 & 77.1 & 83.74 & NC_021962 & Kong 2015 \\
\hline Sphingidae & Sphinx morio & 15,299 & 81.17 & 79.84 & 84.8 & NC_020780 & Min 2013 \\
\hline Noctuidae & Spodoptera exigua & 15,365 & 80.93 & 79.47 & 85.15 & NC_019622 & Qiu-Ling 2013 \\
\hline Noctuidae & Spodoptera litura & 15,388 & 80.98 & 79.55 & 84.71 & $\mathrm{NC}_{-} 022676$ & Wan 2013 \\
\hline Crambidae & Spoladea recurvalis & 15,273 & 80.89 & 79.37 & 85.54 & NC_027443 & He 2014 \\
\hline Drosophilidae & Drosophila melanogaster & 19,517 & 82.16 & 77.23 & 81.9 & U37541 & Clary 1982 \\
\hline
\end{tabular}




\section{Results}

\subsection{Genome Composition and Base Structure}

The complete mitogenome of $B$. hearseyi was $15,442 \mathrm{bp}$ in length (GenBank accession number KU884326), which is longer than the average length of sequenced lepidopteran mitogenomes ((Figure 1). The mitogenome encoded 37 genes, including 13 PCGs (COX1-3, COB, NAD1-6 and 4L, and ATP6 and 8), 22 tRNA genes, and 2 rRNA genes. Among them, 14 genes (including 4 PCGs, namely, ND1, ND4, ND4L, and ND5), 8 tRNA genes (trnF, $\operatorname{trn} H, \operatorname{trn} P, \operatorname{trnL1}, \operatorname{trn} V, \operatorname{trn} Q, \operatorname{trn} C$, and $\operatorname{trn} Y)$, and 2 rRNA genes were encoded by the $\mathrm{L}$-strand. The 23 remaining genes were encoded by the $\mathrm{H}$-strand. Both the location and the structure of PCGs, tRNA genes, and rRNA genes were considered conserved.

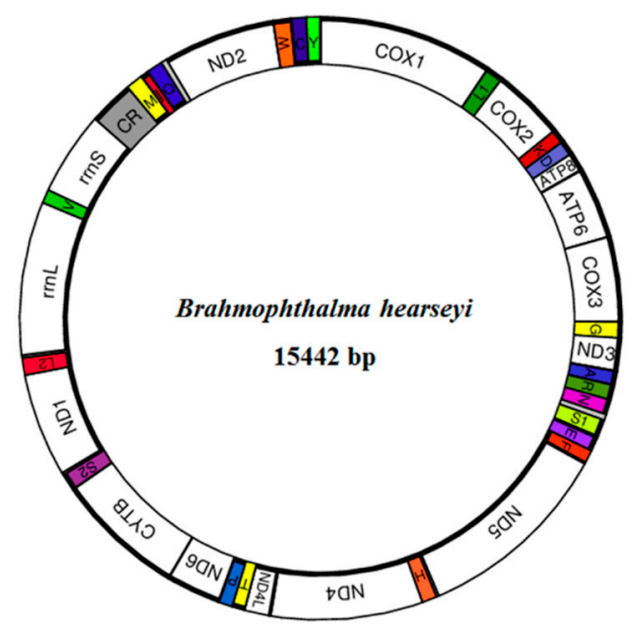

Figure 1. Circular map of the Brahmophthalma hearseyi mitochondrial genome. CR refers to the A + T-rich region.

There were six gene overlaps (1-25 bp in size) and 19 intergenic spacers (1-49 bp in length) in the mitogenome (Supplementary Table S2). The fragment with the most overlap occurred between $\operatorname{trnL} 2$ and $r r n L$, and there was a $7 \mathrm{bp}$ overlapping fragment between ATP8 and ATP6. The longest spacer was present between $t r n N$ and $t r n S 1$ (Supplementary Table S2).

The nucleotide composition of the B. hearseyi mitogenome was as follows: $\mathrm{T}(40.67 \%)$, A $(40.13 \%), C(11.72 \%)$, and G (7.47\%). The A + T content, consistent with the characteristic of a strong $\mathrm{A}+\mathrm{T}$ bias in insect mitogenomes, was $80.81 \%$ across the entire mitogenome, $79.27 \%$ in PCGs, $81.82 \%$ in tRNA genes, and $83.87 \%$ in rRNA genes (Supplementary Table S3). GC skewness was considerably higher than that of AT skewness across the whole mitogenome. The values of AT and GC skewness were -0.007 and -0.221 , respectively. Moreover, the $\mathrm{T}$ base content was higher than that of $\mathrm{A}$, and the $\mathrm{C}$ base content was higher than that of $\mathrm{G}$.

\subsection{PCGs}

The A + T content in PCGs was $79.21 \%$. which was significantly higher than that of $\mathrm{G}+\mathrm{C}$. In addition, the A $+\mathrm{T}$ content at the third codon position was the highest (93.33\%) (Supplementary Table S3), which is similar to that in other insect mitogenomes $[6,34,35]$. GC skewness was lower than AT skewness in 13 PCGs, which was in contrast to that across the whole mitogenome. AT skewness was -0.160 , and GC skewness was 0.025 . In lepidopteran mitogenomes, the AT skewness values of PCGs are all negative, while the values of GC skewness are either negative or positive.

The relative synonymous codon usage was calculated using MEGA5.0. The results showed that amino acids with two synonymous codons showed a high usage frequency of A or $U$ at the third codon position (Supplementary Table S4). 
The codon usage analysis showed the most frequently used codon was UUA (L), which was followed by AUU (I), UUU (F), AUA (I), AAU (N), and UAU (Y). Moreover, the analysis of the amino-acid composition showed that the Leu amount $(15.56 \%)$ was the highest, followed by Ile (11.99\%), Phe (10.02\%), and Ser $(8.95 \%)$. The Cys amount was lowest, at only $0.78 \%$ (Supplementary Table S5).

\section{3. $r R N A$ and $t R N A$ Genes}

The two rRNA genes ( $r r n L$ and $r r n S$ ) of the $B$. hearseyi mitogenome were 1377 and $780 \mathrm{bp}$ in length and were located between $\operatorname{trn} L$ and $\operatorname{trn} V$ and between $\operatorname{trn} V$ and the $\mathrm{A}+\mathrm{T}$-rich region, respectively. The base composition analysis showed that the $\mathrm{A}+\mathrm{T}$ content of rRNA genes was $83.87 \%$. The $\mathrm{A}+\mathrm{T}$ bias was obvious, and the AT skewness and GC skewness were -0.019 and -0.397 , respectively. The length, location, and base composition of the two rRNA genes were similar to those of other lepidopteran insects (Supplementary Figure S1) [6,7,35-38].

The total length of the $22 \mathrm{tRNA}$ genes of the $B$. hearseyi mitogenome was $1480 \mathrm{bp}$, of which the longest was trnK with $71 \mathrm{bp}$, and the shortest was trnY with only $63 \mathrm{bp}$. All of the tRNA genes, except for $\operatorname{trnS1}$ and $\operatorname{trnS2}$, were folded into a typical cloverleaf structure; trnS1 lacked the "DHU" arm, whereas trnS2 exhibited two mismatched base pairs in the anticodon stem. However, $\operatorname{trnL1}(\mathrm{CUN})$ and $\operatorname{trn} A$ contained a U-U mismatch in the recipient stem. This is consistent with the results that were obtained in other lepidopteran insects. DHU and TYC stems were 3-9 bp in length, the anticodon stems were $9 \mathrm{bp}$, and trnL2 was $11 \mathrm{bp}$. The DHU arm of trnS1 was simplified as a loop, which is identical to that of other lepidopteran insects (Supplementary Figure S2) [7,39,40].

\subsection{A+T-Rich Region}

The A + T-rich region of $B$. hearseyi had a length of $455 \mathrm{bp}$ between $r r n S$ and $\operatorname{trnM}$ (Supplementary Figure S3 and Supplementary Table S2), with a high A + T content of $95.6 \%$, while the G $+\mathrm{C}$ content was only $4.40 \%$. The AT skewness for the control region was slightly negative $(-0.085)$, indicating a higher occurrence of $\mathrm{T}$ compared with A nucleotides. The location, size, and structure of the A + T-rich region in mtDNA were not conserved.

The A + T-rich region of the $B$. hearseyi mitogenome featured an "ATAGA" motif that is similar to most Lepidopteran mitogenomes, an 18-nucleotide poly-T stretch following the "ATAGA" motif, and two "TA" short tandem repeats (STRs). There were two copies of $237 \mathrm{bp}$ tandem repeats that were found in the A + T-rich region of $B$. hearseyi using the tandem repeats finder (Supplementary Figure S3).

\subsection{Phylogenetic Analysis}

$\mathrm{BI}$ and NJ trees using the complete mitogenome of 25 species sequences were computed using the best-fit model of GTR + G + I [41].

In our study, the phylogenetic trees were constructed using two datasets (13 PCGs and two rRNAs using the NJ and BI methods (Figure 2). The results of the four trees were almost identical. The two trees that were constructed using the NJ method exhibited the lowest bootstrap values (44 and 14). These results indicate that Brahmaeidae was at one distinct branch, while Sphingidae and Brahmaeidae were separated from the Bombycoidea superfamily. The results of the four trees were similar when branches with low bootstrap values were adjusted. The phylogenetic relationships among these five families were $($ Brahmaeidae + Lasiocampidae $)+($ Bombycidae $+($ Sphingidae + Saturniidae $))$. Hence, Brahmaeidae and Lasiocampidae exhibited a close genetic relationship. 


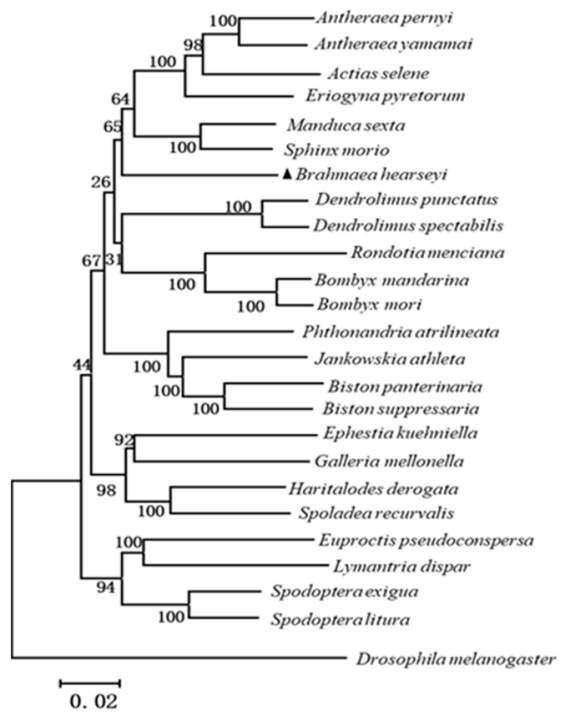

(A)

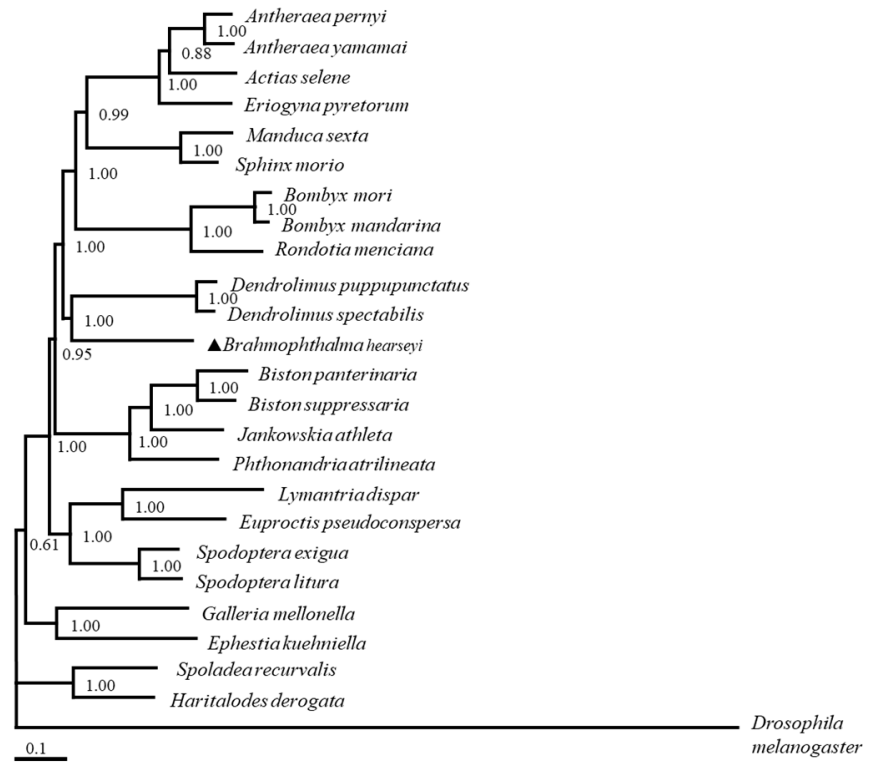

(C)

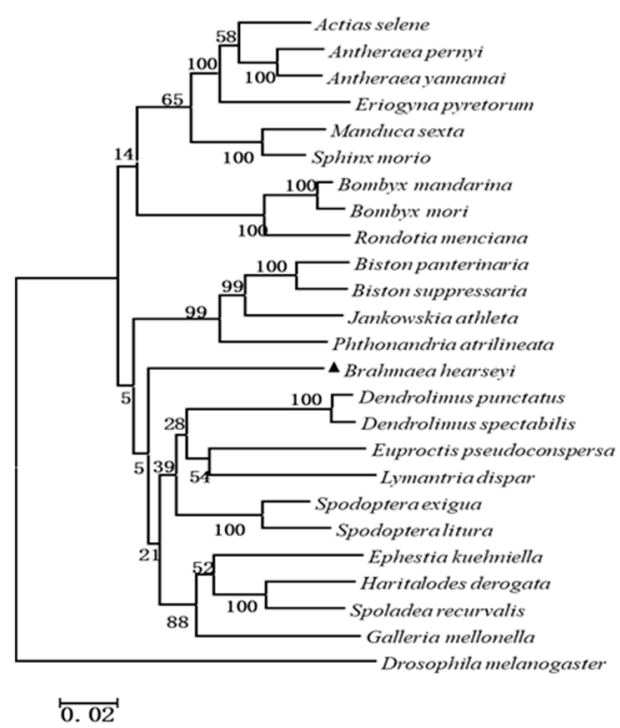

(B)

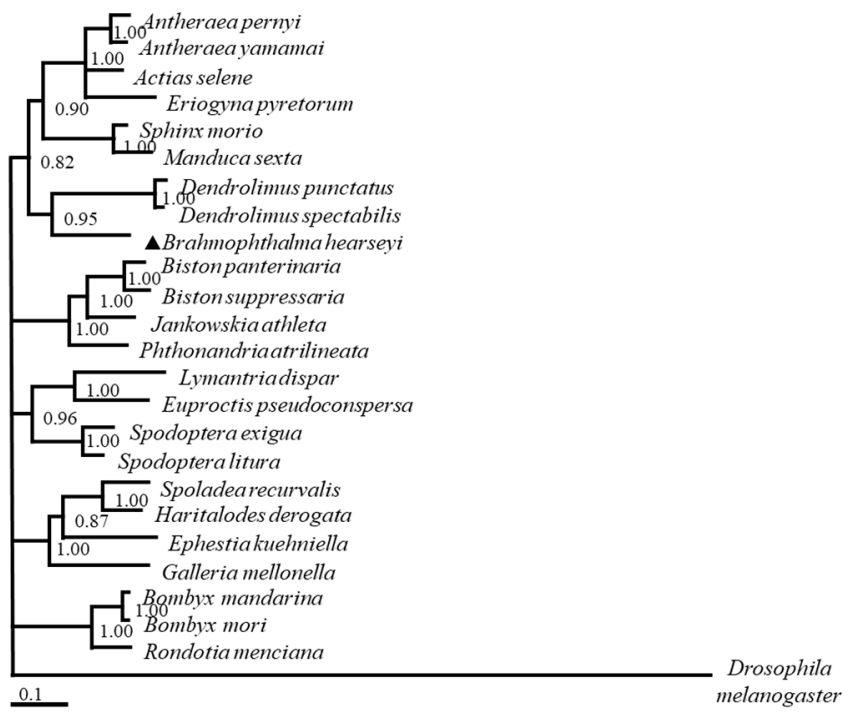

(D)

Figure 2. (A) Neighbor-joining tree based on the PCG dataset; (B) Neighbor-joining tree based on the rRNA dataset; (C) Bayesian inference tree based on the PCG dataset; (D) Bayesian inference tree based on the rRNA dataset.

\section{Discussion}

The mitogenome composition and base structure of $B$. hearseyi revealed similar results to other Lepidoptera insects $[9,40,42-44]$. In the Lepidopteran mitogenome, the number, location, the length of gene overlap, and the intergenic regions affect changes in the size of the entire mitogenome, with certain differences between species. The longest gene overlap regions (61 bp) and the longest intergenic regions (222 bp) were found in the mitogenome of Adoxophyes honmai [45]. In most Lepidoptera, there is a $7 \mathrm{bp}$ length overlap between ATP8 and ATP6. Studies have shown that there is polycistronic transcription of the ATP8 / ATP6 gene [46]. These overlaps are transcribed together, probably because the mRNA of the ATP8 gene is too short, and the translation efficiency is very low [5]. Instead, the complete start codon and stop codon were found on the complementary strand of the $314 \mathrm{bp}$ intergenic sequence of Triatoma dimidata, which may encode an unknown gene. 
The nucleotide composition of the $B$. hearseyi mitogenome was as follows: $\mathrm{T}(40.67 \%), \mathrm{A}$ $(40.13 \%), C(11.72 \%)$, and G $(7.47 \%)$. The A + T content, consistent with the characteristic of a strong $\mathrm{A}+\mathrm{T}$ bias in insect mitogenomes, was $80.81 \%$ across the entire mitogenome, $79.27 \%$ in PCGs, $81.82 \%$ in $t R N A$ genes, and $83.87 \%$ in $r R N A$ genes (Supplementary Table S3). GC skewness was considerably higher than AT skewness across the whole mitogenome. The values of AT and GC skewness were -0.007 and -0.221 , respectively. Moreover, the T base content was higher than that of $\mathrm{A}$, and the $\mathrm{C}$ base content was higher than that of $\mathrm{G}$.

In addition, the $\mathrm{A}+\mathrm{T}$ content at the third codon position was highest $(93.33 \%)$ (Supplementary Table S3), which is similar to that in other insect mitogenomes [6,34,35]. Most PCGs were initiated with a typical ATN start codon: ATG for ATP6, COX3, ND4, ND4L, CYTB, and ND1, and ATT for ND3, ND5, and ND2. The four other PCGs, namely, COX1, COX2, ATP8, and ND6, used CGA, GTG, ATC, and ATA as the start codons, respectively $[6,7,41]$. A total of 11 of the PCGs were terminated with the stop codon TAA, but COX2 and ND5 were terminated with the incomplete stop codon T. This phenomenon exists in all sequenced lepidopteran mitogenomes. The formation of an incomplete stop codon may be attributed to post-transcriptional modification, such as polyadenylation, during the mRNA maturation process [6,44,47].

The analysis of amino-acid composition showed that the Leu amount $(15.56 \%)$ was the highest, followed by Ile (11.99\%), Phe (10.02\%), and Ser (8.95\%). The Cys amount was lowest, at only $0.78 \%$ (Supplementary Table S5). Leu is a hydrophobic amino acid, which may be related to most proteins that are encoded by mitogenomes being transmembrane proteins. Among the 20 amino acids of Lepidoptera insects, Cys content is lowest, which indicates that the amino-acid usage bias of the mitochondrial protein genes of Lepidoptera insects is relatively severe. The length, location, and base composition of the two rRNA genes were similar to those of other lepidopteran insects $[6,7,35-38,48]$ (Supplementary Figure S1). DHU and TYC stems were 3-9 bp in length, anticodon stems were $9 \mathrm{bp}$, and trnL2 was $11 \mathrm{bp}$. The DHU arm of trnS1 was simplified as a loop, which was identical to that of other lepidopteran insects [7,40,41] (Supplementary Figure S2).

The mitogenome A + T-rich region of most lepidopteran insects is located between $r r n S$ and $t r n M$, a variable location that is caused by frequent tRNA rearrangements [4]. The mitogenome A + T-rich regions of Lepidoptera insects show abundant content and length polymorphism, with an average A + T content of up to $93.5 \%$ [49]. This indicates that the polymorphism of the size of the insect mitochondrial A + T-rich region may be due to the insertion/deletion of short tandem repeats $(<500 \mathrm{bp})$ or the size of the intergenic region $[4,36]$. The A + T-rich regions of Somena scintillans and Triuncina daii also revealed two "TA" short repeats $[50,51]$. The A + T-rich region tandem repeats may be caused by nonhomologous recombination that is caused by sliding replication or unequal exchange [52,53]. However, the typical poly-A structure was deleted near the end of trnM. As the $\mathrm{A}+\mathrm{T}$-rich region is a noncoding region, the degree of variation is high. These conserved structural units differ greatly in the insect mitogenome, which may be related to mtDNA replication and transcription [54].

In our study, the phylogenetic relationships among these five families were (Brahmaeidae + Lasiocampidae) + (Bombycidae + (Sphingidae + Saturniidae) ) (Figure 2). Hence, Brahmaeidae and Lasiocampidae exhibited a close genetic relationship. Heppner and many taxonomists used traditional classification methods according to the morphology and structure and indicated Sphingidae as a superfamily [16]. Furthermore, Tillyard [55], Kuznetzov and Stekolnikov [56], and Minet [57] believed that Lasiocampidae independently belongs to the Lasiocampoidea superfamily. Our study supports that Brahmaeidae belongs to the Lasiocampoidea superfamily, instead of the Bombycoidea superfamily. Therefore, this study supports the classification that was proposed by Scoble [15] and Brock [58], whereby both Brahmaeidae and Lasiocampidae belong to the Bombycoidea superfamily. 


\section{Conclusions}

The complete mitochondrial genome (mitogenome) of $B$. hearseyi was sequenced using long-PCR and primer-walking methods. Its biological taxonomic status was determined by phylogenetic analysis. This mitogenome is a typical circular molecule that is made up of 15,442 bp, which includes 13 protein-coding genes (PCGs), 2 ribosomal RNA (rRNA) genes, 22 transfer RNA (tRNA) genes, and an A + T-rich region (456 bp). All of the tRNA genes, except for $t r n S 1$ and $t r n S 2$, display a typical cloverleaf structure; trnS1 lacks the "DHU" arm, whereas trnS2 exhibits two mismatched base pairs in the anticodon stem. In the A + T-rich region of the mitogenome, the "ATAGA" motif, two copies of $237 \mathrm{bp}$ tandem repeats, and two "TA" short tandem repeats were found. Phylogenetic analyses showed that $B$. hearseyi is clustered into Brahmaeidae. The phylogenetic relationships are $($ Brahmaeidae + Lasiocampidae $)+($ Bombycidae + (Sphingidae + Saturniidae) $)$. Therefore, this study enriches the molecular biology data of Brahmaeidae, providing a theoretical basis for the identification of Brahmaeidae, as well as for the control of $B$. hearseyi.

Supplementary Materials: The following are available online at https:/ / www.mdpi.com/article/10 .3390 /insects12110973/s1, Figure S1: Predicted secondary structure of the Brahmophthalma hearseyi 2 rRNA genes., Figure S2: Predicted secondary clover-leaf structure of the Brahmophthalma hearseyi 22 tRNA genes. Figure S3: Features of the AT-rich region of Brahmophthalma hearseyi. Table S1: Universal primer sequences and condition of Long-distance PCR used to amply the mitochondrial genome of Brahmophthalma hearseyi, Table S2: Organization of the Brahmophthalma hearseyi mitochondrial genome, Table S3: Nucleotide composition features within Brahmophthalma hearseyi mitochondrial genome Table S4: Codon usage of the protein-coding genes of the Brahmophthalma hearseyi mitogenomes. Table S5: Amino acid composition of 13 proteins of the Brahmophthalma hearseyi mitochondrial genome.

Author Contributions: Conceptualization, T.X.; methodology, S.G.; validation, S.Y. and S.G.; formal analysis, S.Y.; investigation, S.C.; resources, B.X and Z.Z.; data curation, S.Y.; writing-original draft preparation, S.Y.; writing-review and editing, S.Y.; visualization, Z.Z. and B.X.; supervision, B.X.; project administration, B.X. All authors have read and agreed to the published version of the manuscript.

Funding: This study was supported by the Key R\&D program of Jiangxi Province (20194ABC28007; 20203BBF63041) and the National Natural Science Foundation of China $(31860601,31760621)$.

Institutional Review Board Statement: Not applicable.

Informed Consent Statement: Not applicable.

Data Availability Statement: The data presented in this study are available in supplementary material.

Acknowledgments: We thank Ling Zhong, Lei Tu, Zhaohui Zhang, Rui Cao for their insightful comments and useful suggestions.

Conflicts of Interest: The authors declare no conflict of interest.

\section{References}

1. Avise, J.C.; Arnold, J.; Ball, R.M.; Bermingham, E.; Lamb, T.; Neigel, J.E.; Saunders, N.C. Intraspecific phylogeography: The mitochondrial DNA bridge between population genetics and systematics. Annu. Rev. Ecol. Syst. 1987, 18, 489-522. [CrossRef]

2. Graeber, M.B.; Müller, U. Recent developments in the molecular genetics of mitochondrial disorders. J. Neurol. Sci. 1998, 153, 251-263. [CrossRef]

3. Liu, X.H.; Jian, X.U.; Zhou, J.; Xiao-Ping, L.U. The morphology of Brahmophthalma hearseyi white and the characters in Suzhou. J. Chang. Inst. Technol. 2009, 23, 69-70.

4. Zhu, H.F.; Wang, L.Y. Chinese Brahmaeidae. Acta Entomol. Sin. 1977, 20, 83-84.

5. Shimazaki, A.; Miyashita, T. Deer browsing reduces leaf damage by herbivorous insects through an induced response of the host plant. Ecol. Res. 2002, 17, 527-533. [CrossRef]

6. Boore, J.L. Animal mitochondrial genomes. Nucleic Acids Res. 1999, 27, 1767-1780. [CrossRef]

7. Taanman, J.W. The mitochondrial genome: Structure, transcription, translation and replication. Biochim. Biophys. Acta (BBA)Bioenerg. 1999, 1410, 103-123. [CrossRef] 
8. Cameron, S.L.; Whiting, M.F. The complete mitochondrial genome of the tobacco hornworm, Manduca sexta, (Insecta: Lepidoptera: Sphingidae), and an examination of mitochondrial gene variability within butterflies and moths. Gene 2008, 408, 112-123. [CrossRef]

9. Jiang, S.T.; Hong, G.Y.; Yu, M.; Li, N.; Yang, Y.; Liu, Y.Q.; Wei, Z.J. Characterization of the complete mitochondrial genome of the giant silkworm moth, Eriogyna pyretorum (Lepidoptera: Saturniidae). Int. J. Biol. Sci. 2009, 5, 351-365. [CrossRef]

10. Cameron, S.L. Insect mitochondrial genomics: Implications for evolution and phylogeny. Annu. Rev. Entomol. 2014, 59, 95-117. [CrossRef]

11. Kong, W.; Yang, J. The complete mitochondrial genome of Rondotia menciana (Lepidoptera: Bombycidae). J. Insect Sci. 2015, 15, 48. [CrossRef]

12. Peng, X.Y.; Zhou, P.; Qiang, Y.; Qian, Z.Q. Characterization of the complete mitochondrial genome of Bombyx huttoni (Lepidoptera: Bombycidae). Mitochondrial DNA 2015, 27, 4112-4113. [CrossRef]

13. Park, J.S.; Kim, M.J.; Kim, I. The complete mitochondrial genome of the moon moth, Actias aliena (Lepidoptera: Saturniidae). Mitochondrial DNA Part A 2016, 27, 149-150. [CrossRef]

14. Shantibala, T.; Victor, T.; Luikham, R.; Arunkumar, K.P.; Debaraj Sharma, H.; Lokeshwari, R.K.; Kim, I. Complete mitochondrial genome of the wild eri silkworm, Samia canningi (Lepidoptera: Saturniidae). Mitochondrial DNA Part A 2016, 27, 844-845. [CrossRef]

15. Ackery, P.R. Systematic and faunistic studies on butterflies. In Symposia of the Royal Entomological Society of London; National Agricultural Library: Beltsville, MD, USA, 1984; pp. 304-306.

16. Harvey, D.J. Higher Classification of the Nymphalidae, Appendix B. The Development and Evolution of Butterfly Wing Patterns; Nijhout, H.F., Ed.; Smithsonian Institution Press: Washington, DC, USA, 1991; pp. 255-273.

17. Scoble, M.J. The Lepidoptera. Form, Function and Diversity; Oxford University Press: Oxford, UK, 1992; pp. 1-2.

18. Heppner, J.B. Classification of Lepidoptera: Part 1: Introduction; Holarctic Lepidoptera; Association for Tropical Lepidoptera: Statesboro, GA, USA, 1998; p. 5.

19. Wang, H.; Wahlberg, N.; Holloway, J.D.; Bergsten, J.; Fan, X.; Janzen, D.H.; Hallwachs, W.; Wen, L.; Wang, M.; Nylin, S. Molecular phylogeny of Lymantriinae (Lepidoptera, Noctuoidea, Erebidae) inferred from eight gene regions. Cladistics 2015, 31, 579-592. [CrossRef]

20. Mell, R. Beitrage Zur Fauna Sinica. V. Die Brahmaeiden und Eupterotiden Chinas; Deut. Ent. Zeit.: Berlin, Germany, $1929 ;$ pp. 337-487.

21. Bryk, F. Brahmaeidae Hampson. Arkiv for Zoologi. Groszschmetterling Vom Korea 1949, 41, 1-125.

22. Sauter, W. Zur systematis chen Stellung ron Brahmaea europaea Hartig (Lep. Brahmaeidae). Mitt. Schweiz. Ent. Ges. 1967, 40, 125-129.

23. Hao, H.L.; Zhang, X.R.; Yang, J.K. Genus and Distribution of Brahmaeidae (Lepidoptera) from China. J. China Agric. Univ. 1999, 4, 37-42.

24. Hao, J.; Li, C.; Sun, X.; Yang, Q. Phylogeny and divergence time estimation of cheilostome bryozoans based on mitochondrial 16S rRNA sequences. Chin. Sci. Bull. 2005, 50, 1205-1211. [CrossRef]

25. Simon, C.; Frati, F.; Beckenbach, A.; Crespi, B.; Liu, H.; Flook, P. Evolution, weighting, and phylogenetic utility of mitochondrial gene sequences and a compilation of conserved polymerase chain reaction primers. Ann. Entomol. Soc. Am. 1994, 87, 651-701. [CrossRef]

26. Simmons, R.B.; Weller, S.J. Utility and evolution of cytochrome b in insects. Mol. Phylogenetics Evol. 2001, 20, 196-210. [CrossRef] [PubMed]

27. Singh, V.K.; Mangalam, A.K.; Dwivedi, S.; Naik, S. Primer premier: Program for design of degenerate primers from a protein sequence. Biotechniques 1998, 24, 318-319. [CrossRef]

28. Clewley, J.P. Macintosh sequence analysis software. Mol. Biotechnol. 1995, 3, 221-224. [CrossRef] [PubMed]

29. Bernt, M.; Donath, A.; Jühling, F.; Externbrink, F.; Florentz, C.; Fritzsch, G.; Stadler, P.F. MITOS: Improved de novo metazoan mitochondrial genome annotation. Mol. Phylogenetics Evol. 2013, 69, 313-319. [CrossRef] [PubMed]

30. Kumar, S.; Tamura, K.; Nei, M. MEGA3: Integrated software for molecular evolutionary genetics analysis and sequence alignment. Brief. Bioinform. 2004, 5, 150-163. [CrossRef]

31. Thompson, J.D.; Gibson, T.J.; Plewniak, F.; Jeanmougin, F.; Higgins, D.G. The CLUSTAL_X windows interface: Flexible strategies for multiple sequence alignment aided by quality analysis tools. Nucleic Acids Res. 1997, 25, 4876-4882. [CrossRef] [PubMed]

32. Saitou, N.; Nei, M. The neighbor-joining method: A new method for reconstructing phylogenetic trees. Mol. Biol. Evol. 1987, 4, 406-425.

33. Yang, Z.; Rannala, B. Bayesian phylogenetic inference using DNA sequences: A Markov Chain Monte Carlo method. Mol. Biol. Evol. 1997, 14, 717-724. [CrossRef]

34. Tang, M.; Tan, M.; Meng, G.; Yang, S.; Su, X.; Liu, S.; Zhou, X. Multiplex sequencing of pooled mitochondrial genomes-A crucial step toward biodiversity analysis using mito-metagenomics. Nucleic Acids Res. 2014, 42, e166. [CrossRef]

35. Zhang, Y.L.; Wu, A.Q. The complete mitochondrial genome of Bombyx mori strain Chunyun (Lepidoptera: Bombycidae). Mitochondrial DNA 2016, 27, 4082-4083. [CrossRef]

36. Yukuhiro, K.; Sezutsu, H.; Itoh, M.; Shimizu, K.; Banno, Y. Significant levels of sequence divergence and gene rearrangements have occurred between the mitochondrial genomes of the wild mulberry silkmoth, Bombyx mandarina, and its close relative, the domesticated silkmoth, Bombyx mori. Mol. Biol. Evol. 2002, 19, 1385-1389. [CrossRef] 
37. Qin, J.; Zhang, Y.; Zhou, X.; Kong, X.; Wei, S.; Ward, R.D.; Zhang, A.B. Mitochondrial phylogenomics and genetic relationships of closely related pine moth (Lasiocampidae: Dendrolimus) species in China, using whole mitochondrial genomes. BMC Genom. 2015, 16, 1. [CrossRef] [PubMed]

38. Yang, M.; Song, L.; Shi, Y.; Yin, Y.; Wang, Y.; Zhang, P.; Chen, J.; Lou, L.; Liu, X. The complete mitochondrial genome of a medicinal insect, Hydrillodes repugnalis (Lepidoptera: Noctuoidea: Erebidae), and related phylogenetic analysis. Int. J. Biol. Macromol. 2019, 123, 485-493. [CrossRef]

39. Liu, Q.N.; Zhu, B.J.; Dai, L.S.; Wei, G.Q.; Liu, C.L. The complete mitochondrial genome of the wild silkworm moth, Actias selene. Gene 2012, 505, 291-299. [CrossRef]

40. Yang, L.; Wei, Z.J.; Hong, G.Y.; Jiang, S.T.; Wen, L.P. The complete nucleotide sequence of the mitochondrial genome of Phthonandria atrilineata (Lepidoptera: Geometridae). Mol. Biol. Rep. 2009, 36, 1441-1449. [CrossRef] [PubMed]

41. MaKS, N. Molecular Evolution and Phylogenetics; Oxford University Press: New York, NY, USA, 2000.

42. Chen, M.M.; Li, Y.; Chen, M.; Wang, H.; Li, Q.; Xia, R.X.; Qin, L. Complete mitochondrial genome of the atlas moth, Attacus atlas (Lepidoptera: Saturniidae) and the phylogenetic relationship of Saturniidae species. Gene 2014, 545, 95-101. [CrossRef]

43. Hong, G.; Jiang, S.; Yu, M.; Yang, Y.; Li, F.; Xue, F.; Wei, Z. The complete nucleotide sequence of the mitochondrial genome of the cabbage butterfly, Artogeia melete (Lepidoptera: Pieridae). Acta Biochim. Biophys. Sin. 2009, 41, 446-455. [CrossRef]

44. Kim, S.R.; Kim, M.I.; Hong, M.Y.; Kim, K.Y.; Kang, P.D.; Hwang, J.S.; Kim, I. The complete mitogenome sequence of the Japanese oak silkmoth, Antheraea yamamai (Lepidoptera: Saturniidae). Mol. Biol. Rep. 2009, 36, 1871-1880. [CrossRef]

45. Lee, E.S.; Shin, K.S.; Kim, M.S.; Park, H.; Cho, S.; Kim, C.B. The mitochondrial genome of the smaller tea tortrix Adoxophyes honmai (Lepidoptera: Tortricidae). Gene 2006, 373, 52-57. [CrossRef]

46. Sima, Y.H.; Chen, M.; Yao, R.; Li, Y.P.; Liu, T.; Jin, X.; Liu, Y.Q. The complete mitochondrial genome of the Ailanthus silkmoth, Samia cynthia cynthia (Lepidoptera: Saturniidae). Gene 2013, 526, 309-317. [CrossRef] [PubMed]

47. Liu, Y.; Li, Y.; Pan, M.; Dai, F.; Zhu, X.; Lu, C.; Xiang, Z. The complete mitochondrial genome of the Chinese oak silkmoth, Antheraea pernyi (Lepidoptera: Saturniidae). Acta Biochim. Biophys. Sin. 2008, 40, 693-703. [CrossRef]

48. Coates, B.S.; Sumerford, D.V.; Hellmich, R.L. Partial mitochondrial genome sequences of Ostrinia nubilalis and Ostrinia furnacalis. Int. J. Biol. Sci. 2005, 1, 13-18. [CrossRef]

49. Taylor, M.F.; McKechnie, S.W.; Pierce, N.; Kreitman, M. The lepidopteran mitochondrial control region: Structure and evolution. Mol. Biol. Evol. 1993, 10, 1259-1272. [PubMed]

50. Liu, Y.; Xin, Z.Z.; Zhu, X.Y.; Zhao, X.M.; Wang, Y.; Tang, B.P.; Zhang, H.B.; Zhang, D.Z.; Zhou, C.L.; Liu, Q.N. The complete mitochondrial genome of Euproctis similis (Lepidoptera: Noctuoidea: Erebidae) and phylogenetic analysis. Int. J. Biol. Macromol. 2017, 105 Pt 1, 219-227. [CrossRef]

51. Li, J.; Zhao, Y.; Lin, R.; Zhang, Y.; Hu, K.; Li, Y.; Huang, Z.; Peng, S.; Ding, J.H.; Geng, X.X.; et al. Mitochondrial genome characteristics of Somena scintillans (Lepidoptera: Erebidae) and comparation with other Noctuoidea insects. Genomics 2019, 111, 1239-1248. [CrossRef]

52. Zhang, D.X.; Hewitt, G.M. Insect Mitochondrial Control rengion: A Review of structure, Evolitionar ystudies. Biochem. Syst. Ecol. 1997, 25, 99-120. [CrossRef]

53. Wu, Q.L.; Gong, Y.J.; Gu, Y.; Wei, S.J. The complete mitochondrial genome of the beet armyworm Spodoptera exigua (Hübner) (Lepodiptera: Noctuidae). Mitochondrial DNA 2013, 24, 31-33. [CrossRef] [PubMed]

54. Crozier, R.H.; Crozier, Y.C. The mitochondrial genome of the honeybee Apis mellifera: Complete sequence and genome organization. Genetics 1993, 133, 97-117. [CrossRef]

55. Tillyard, R.J.; Dunstan, B. Mesozoic insects of Queensland; Government Printer: Cumming, AJ, USA, 1924 ; Volume 2.

56. Kuznetzov, V.I.; Stekolnikov, A.A. Comparative and functional morphology of the male genitalia of the bombycoid moths (Lepidoptera, Papilionomorpha: Lasiocampoidea, Sphingoidea, Bombycoidea) and their systematic position. Tr. Zool. Inst. Leningr. 1985, 134, 3-48.

57. Minet, J. Tentative reconstruction of the ditrysian phylogeny (Lepidoptera: Glossata). Insect Syst. Evol. 1991, 22, 69-95. [CrossRef]

58. Brock, J.P. A contribution towards an understanding of the morphology and phylogeny of the Ditrysian Lepidoptera. J. Nat. Hist. 1971, 5, 29-102. [CrossRef] 